ISSN : 2252-3839 (Print)

ISSN : 2549-2403 (On Line)

DOI : 10.28989/compiler.v8i2.538

http://ejournals.stta.ac.id/index.php/compiler/

\title{
ANALYSIS OF COMBINATION KNOWLEDGE ACQUISITION OF HAAR TRAINING FOR OBJECT DETECTION ON THE VIOLA JONES METHOD
}

Haruno Sajati $^{1)}$, Anggraini Kusumaningrum ${ }^{2)}$, Nur Hanifah ${ }^{3)}$

1,2,3 Departemen Informatika, Sekolah Tinggi Teknologi Adisutjipto

Jl. Janti, Blok-R Lanud Adisutjipto Yogyakarta

Email: ${ }^{1}$ harunosajati@ stta.ac.id, ${ }^{2}$ anggraini@stta.ac.id, ${ }^{3}$ hanifsay837@gmail.com

\begin{abstract}
Viola Jones method uses the file classifier to object detection. The training process to create object classifier file requires very high computer resources and time which is directly proportional to the amount of training data. The amount of training data determines the accuracy of object detection. The long training process is caused because the computer has low specifications and the distribution of Haar Training files will speed up the process of vector file formation, minimize errors when cutting Haar features on positive objects and also minimize errors that occur during the training process. The problems that arise next are how to overcome this so that a better knowledge is obtained. This study provides analysis results of the process of merging knowledge acquisition and its effect on the accuracy of object detection using the Viola-Jones method with the final result undetected object decrease 52.62\% and object detected increase $23.78 \%$.
\end{abstract}

Keywords: Knowledge Acquisition, Training, Object Detection, Viola-Jones

\section{Latar Belakang Masalah}

Metode Viola Jones merupakan algoritma yang banyak digunakan untuk melakukan pendeteksian suatu obyek. Haar Training memerlukan dua tipe gambar obyek dalam proses training yang dilakukan, yaitu positive samples yang berisi gambar obyek dan negative samples berisi gambar selain obyek yang ingin dikenali, umumnya berupa gambar background (tembok, pemandangan, lantai dan gambar lainnya). Saat ini banyak yang sudah melakukan penelitian tentang pendeteksi suatu obyek yang bertujuan untuk mengetahui ada atau tidaknya obyek pada suatu gambar dengan menggunakan Metode Viola Jones tersebut [1][2][3][4][5][6], namun dalam kondisi tertentu Haar-cascade mendeteksi obyek palsu sehingga akan memunculkan beberapa kandidat obyek. Obyek palsu ini muncul karena kurangnya data training, penambahan data training akan mengakibatkan lamanya proses Haar Training, memperlama proses pemotongan fitur Haar pada obyek positif dan juga rentan terhadap kesalahan saat melakukan pemotongan fitur Haar pada obyek positif [4]. Proses training yang lama ini diakibatkan karena komputer mempunyai spesifikasi yang rendah dan dengan pembagian file training akan mempercepat proses pembentukan file vector, meminimalisir kesalahan saat melakukan pemotongan fitur Haar pada obyek positif dan juga meminimalisir kesalahan yang terjadi saat melakukan proses training [5][6][13][14]. Permasalahan yang timbul kemudian adalah bagaimana cara penggabungan knowledge acquisition untuk menurunkan kesalahan dalam pendeteksian obyek dan pengaruh dari proses penggabungan knowledge acquisition terhadap akurasi pendeteksian obyek[9][10][11][12][13]. 


\section{Metodologi Penelitian}

\subsection{Metode Viola - Jones}

Dalam framework Viola-Jones disediakan banyak library untuk melakukan proses seleksi fitur, fitur yang merupakan fungsi dasar untuk meningkatkan seleksi dikenal sebagai Haar-Like feature. Viola-Jones memperkenalkan sebuah representasi image baru yang dikenal sebagai Integral Image yang tidak terpisahkan. Dengan metode ini HaarLike features dapat dihitung pada setiap skala atau lokasi dalam waktu yang konstan. Metode Viola-Jones menggabungkan empat kunci utama yaitu Haar-Like Feature, Integral Image, AdaBoost dan Cascade classifier. Gambar 1 merupakan gambar Skema Proses Deteksi Obyek dengan Metode Viola-Jones.

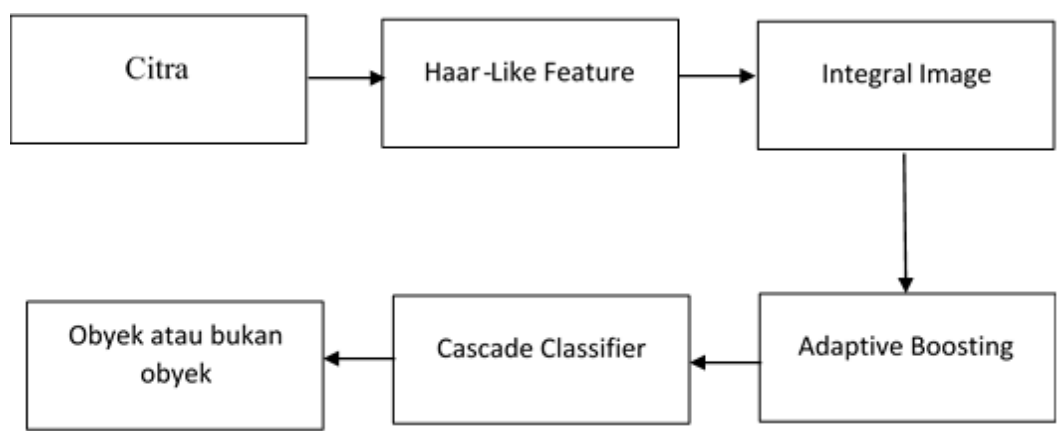

Gambar 1. Skema Proses Deteksi Obyek dengan Metode Viola-Jones.

\subsection{Kebutuhan Data}

Data yang digunakan terbagi dalam 2 bagian yaitu citra positif dan citra negatif. Citra sampel positif yaitu citra sampel yang di dalamnya terdapat objek (flash disk) sebanyak 400 sampel. Sedangkan Citra sampel negatif adalah citra sampel yang di dalamnya tidak terdapat objek yang akan dideteksi dan diambil secara acak sebanyak 1000 sampel. Pemilihan flash disk sebagai obyek penelitian adalah jumlah varian dari flash disk cukup banyak dan keberadaannya mudah ditemukan. Flash disk juga memiliki dimensi fisik yang cukup besar untuk dipindai dalam Region of Interest (ROI) saat pendeteksian obyek.

\subsection{Kebutuhan File Pustaka}

File pustaka yang digunakan pada penelitian ini adalah OpenCV. Open Source Computer Vision Library merupakan software pustaka yang ditujukan untuk pengolahan citra dinamis secara real-time, yang dibuat oleh Intel, dan sekarang didukung oleh Willow Garage dan Itseez. OpenCV dirilis di bawah lisensi permisif BSD. Lisensi BSD adalah keluarga dari lisensi perangkat lunak bebas yang permisif dan memberikan kebebasan sepenuhnya untuk dimanfaatkan secara komersil tanpa perlu mengungkapkan kode sumbernya. OpenCV juga memiliki antar muka yang mendukung bahasa pemrograman $\mathrm{C}++[15]$.

\subsection{Perancangan Sistem}

Gambar 2 merupakan perancangan alur sistem yang digunakan dalam perangkat lunak dari sebuah gambar yang akan diproses untuk di filter menjadi sebuah data output yang berupa file dalam format XML 


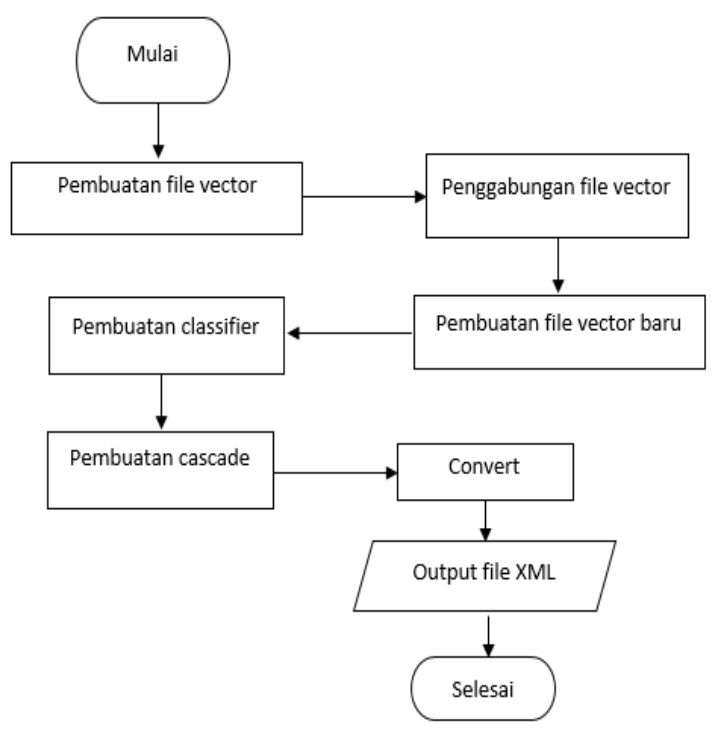

Gambar 2. Proses penggabungan knowledge untuk pendeteksian obyek

. Untuk mendapatkan file XML harus terlebih dahulu mulai pembuatan file vector dengan menggunakan perintah create sample command yang di dalamnya sudah berisi citra positif. Kemudian membuat file vector lain dengan data berbeda yang nantinya akan dilakukan penggabungan vector. Untuk melakukan penggabungan vector akan menghasilkan vector baru hasil dari penggabungan tersebut. Untuk pembuatan classifier nya terlebih dahulu melakukan Haar Training yang di dalamnya terdapat citra negatif dan file vector. File vector hasil penggabungan itulah yang akan digunakan pada proses Haar Training. Proses ini akan membentuk direktori classifier. Kemudian pembentukan cascade dengan cara melakukan perpindahan isi direktori classifier ke dalam direktori cascade. Tahap berikutnya adalah pembentukan file XML melalui proses convert untuk menggabungkan data tersebut menjadi satu file classifier dengan nama haarcascade.xml.

\subsection{Perancangan Pembuatan Haar Like Feature}

Dalam proses penggabungan vector dibutuhkan beberapa File vector yaitu:

1. Sample.vec

File sample.vec berisikan code yang akan dikenali pada library OpenCV untuk mendeteksi kumpulan flash disk kelompok pertama.

2. Sample1.vec

File sample.vec berisikan code yang akan dikenali pada library OpenCV untuk mendeteksi kumpulan flash disk kelompok kedua.

3. Gabungan.vec

File gabungan.vec berisikan code yang akan dikenali pada library OpenCV untuk mendeteksi kumpulan flash disk kelompok gabungan.

\subsection{Proses Pembuatan Cascade}

Tahap pembuatan cascade dilakukan melalui beberapa tahap seperti pembuatan list negatif, pemberian fullpath gambar negatif, pembentukan file negNew.txt, persiapan file positif, pembuatan object info, terbentuk file info.txt, full path untuk file info.txt (rawdata), pembuatan file vector, terbentuk file vector, pembuatan classifier, terbentuk training cascade, penyatuan file cascade menjadi cascade classifier lengkap sampai pada akhirnya keluarlah output berupa file XML. Proses tersebut dilakukan pada jumlah data 
gabungan sebanyak 11 kali percobaan pendeteksian yang memiliki jumlah flash disk berbeda. Pada proses penggabungan ini akan diambil file vector nya saja, file vector tersebut yang bernama sample.vec. File sample.vec ini nantinya merupakan penggabungan antara sample.vec1 dan sample.vec 2.

\subsection{Membuat Folder Gabungan}

Setelah mendapatkan file vector dari beberapa sample data maka selanjutnya dilakukan penggabungan file vector tersebut ke dalam satu folder

\subsection{Membuat File Gabungan Vector}

Setelah file vector yang akan di-combine dikumpulkan ke dalam satu folder, maka tahap selanjutnya adalah menggabungkan 2 vector tersebut ke dalam 1 folder yang nantinya akan menghasilkan 1 vector. Proses melakukan gabungan vector ditunjukkan pada Gambar 4.

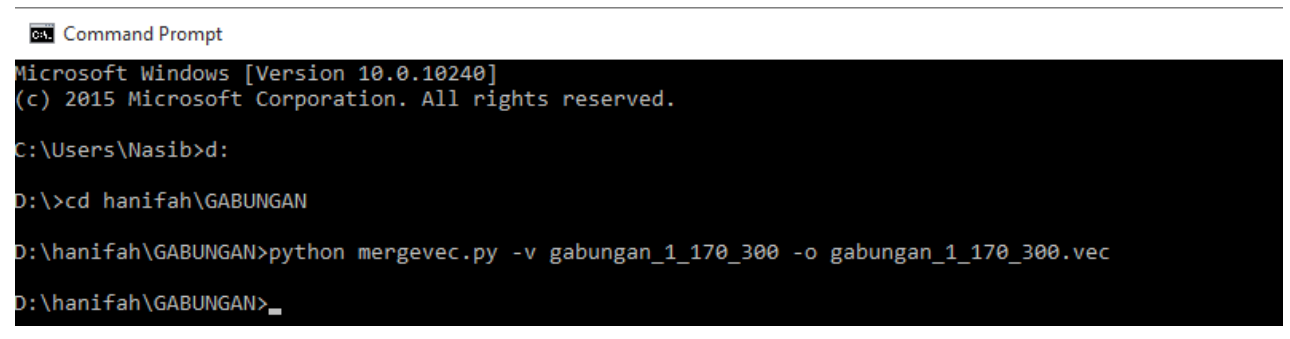

Gambar 4. Proses Penggabungan Vector

Setelah pembuatan vector selesai dilakukan, selanjutnya adalah proses merubah vector yang sebelum digabung menjadi vector yang sudah digabung dan mengubah jumlah gambar positif dan gambar negatif sesuai dengan jumlah yang akan dilakukan proses haar-training. Proses ini akan menghasilkan output XML. File ini yang akan digunakan untuk proses pendeteksian obyek pada tahap berikutnya.

\section{Hasil dan Pembahasan}

\subsection{Implementasi Hasil}

Gambar 6 menunjukkan contoh dan proses perhitungan hasil pendeteksian obyek menggunakan metode Viola Jones.

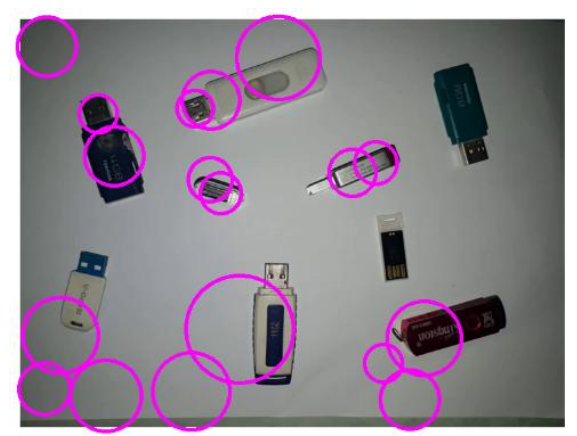

Gambar 6. Hasil Sebelum Penggabungan pada Data Pertama

Dapat dilihat dari gambar 6 yang berhasil terdeteksi 4 flash disk dimana flash disk lebih mendominasi berada di area lingkaran dan yang tidak terdeteksi ada 5 flash disk. 


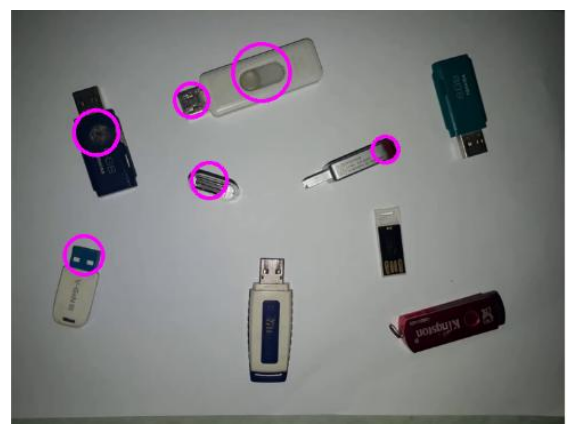

Gambar 7. Hasil Sebelum Penggabungan pada Data Kedua

Dapat dilihat dari gambar 7 yang berhasil terdeteksi 5 flash disk dimana flash disk lebih mendominasi berada di area lingkaran dan yang tidak terdeteksi ada 5 flash disk.

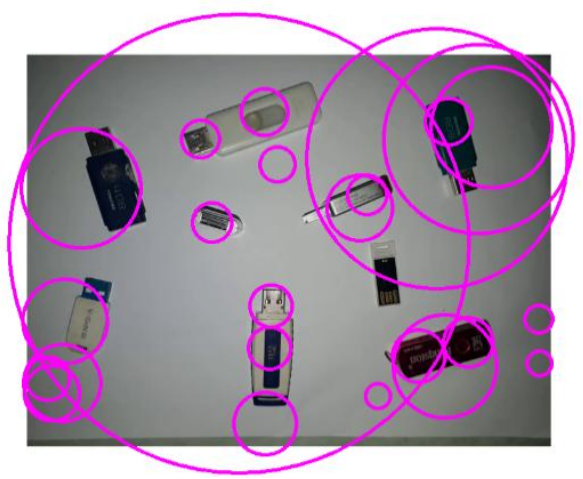

Gambar 8. Hasil Penggabungan

Gambar 8 merupakan hasil pendeteksian menggunakan file classifier yang diperoleh dari penggabungan 2 vector. Hasil percobaan pendeteksian pada Gambar 8 menunjukkan hasil sebanyak enam flash disk dimana flash disk lebih mendominasi berada di area lingkaran dan yang tidak terdeteksi ada 3 flash disk.

\subsection{Analisa hasil Pendeteksian Obyek}

Pada penelitian ini dilakukan pengujian terhadap 10 obyek flash disk dengan jumlah yang berbeda. Perhitungan means dilakukan dengan menjumlahkan data obyek yang tidak terdeteksi/terdeteksi di bagi jumlah flash disk, lalu hasilnya saling dijumlahkan. Hasil penjumlahan means pada data percobaan Vec 1 dan data percobaan Vec 2 pada Tabel 1 dijumlahkan kembali dan dibagi 10. Untuk mengetahui hasil prosentase dapat dihitung dengan cara data gabungan dibagi hasil penjumlahan data 1 dan data 2 lalu dikalikan $100 \%$.

Table 1. Vec Gabungan: N-Pos 40 N-Neg 40

\begin{tabular}{|c|c|c|c|}
\hline $\begin{array}{c}\text { Jumlah } \\
\text { Flash disk }\end{array}$ & $\begin{array}{c}\text { Vec 1: N-Pos 20 N-Neg 40 } \\
\text { (Means) }\end{array}$ & $\begin{array}{c}\text { Vec 2: N-Pos 20 N-Neg 40 } \\
\text { (Means) }\end{array}$ & $\begin{array}{c}\text { Vec Gabungan: N-Pos } \\
\text { 40 N-Neg 40 (Means) }\end{array}$ \\
\hline 1 & 0 & 0 & 0 \\
\hline 2 & 0.5 & 0.5 & 0 \\
\hline 3 & 0.66 & 0.66 & 0.33 \\
\hline 4 & 1 & 1 & 0.5 \\
\hline 5 & 1.8 & 1.2 & 0.4 \\
\hline 6 & 2.166 & 1.5 & 0.66 \\
\hline 7 & 2.571 & 1.85 & 1.142 \\
\hline 8 & 3 & 2.25 & 1.125 \\
\hline
\end{tabular}




\begin{tabular}{|c|c|c|c|}
\hline 9 & 3.222 & 2.55 & 1.222 \\
\hline 10 & 3.4 & 2.8 & 1.1 \\
\hline Means & 1.8319 & 1.431 & 0.6479 \\
\hline
\end{tabular}

Pada Tabel 1 ditunjukkan proses perhitungan jumlah obyek flash disk yang tidak berhasil terdeteksi menggunakan Vec 1 sebesar 1.8319 obyek dan Vec 2 sebesar 1.431 obyek. Dengan menggunakan Vec gabungan, terdapat penurunan jumlah obyek tak terdeteksi dengan rata-rata 0.6479 obyek yang tidak terdeteksi. Jumlah obyek yang tidak terdeteksi menggunakan vector gabungan menurun $64.63 \%$ dibanding vector 1 (Vec1) dan $54.72 \%$ dibanding vector 2 ( $\mathrm{Vec} 2$ ). Akurasi pendeteksian obyek ditunjukkan pada gambar 10.

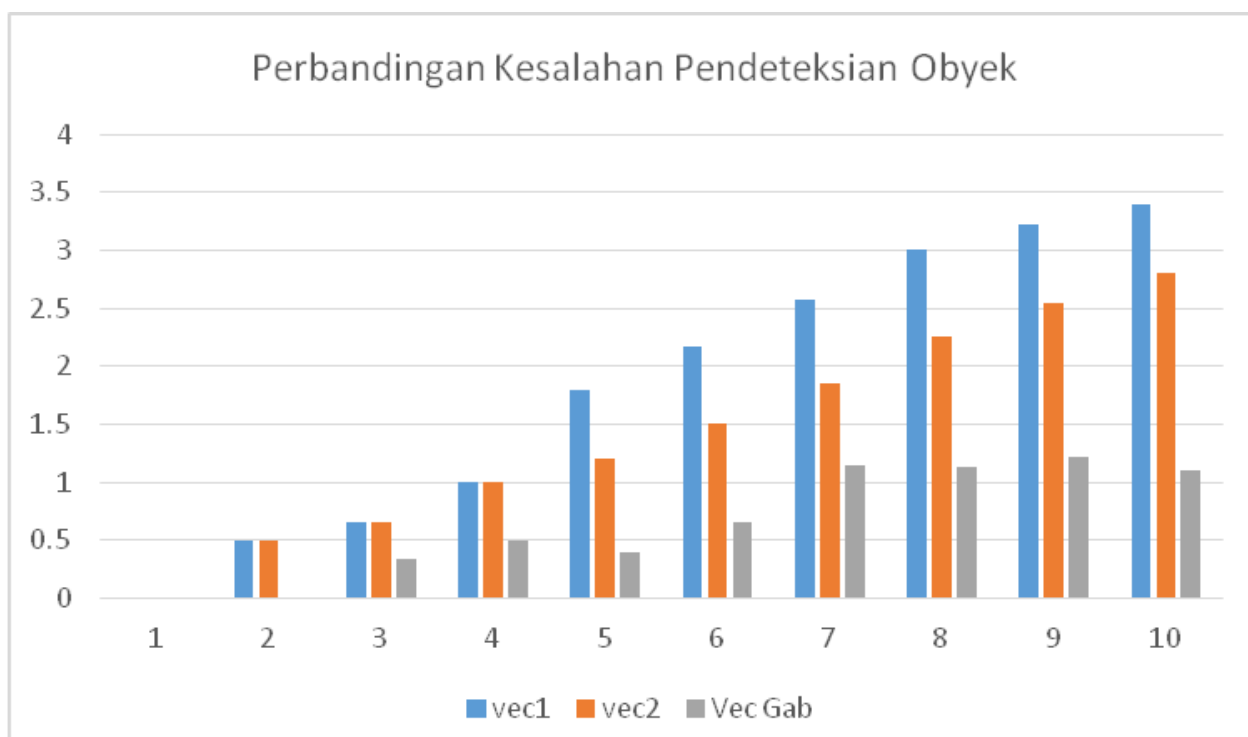

Gambar 10. Perbandingan Kesalahan Pendeteksian Obyek Vec1, Vec2 dan Vec Gabungan

Uji statistik keberhasilan pendeteksian obyek ditunjukkan pada tabel 2.

Tabel 2. Min, Max, Means Vec Gabungan: N-Pos 40 N-Neg 40 Obyek Terdeteksi

\begin{tabular}{|c|c|c|c|c|c|c|c|c|c|c|}
\hline \multirow{3}{*}{ No } & \multirow{3}{*}{$\begin{array}{c}\text { Jumlah } \\
\text { Flash disk }\end{array}$} & \multicolumn{3}{|c|}{ Vec 1: N-Pos 20 } & \multicolumn{3}{c|}{ Vec 2: N-Pos 20 } & \multicolumn{3}{c|}{ Vec Gabungan: N-Pos 40 } \\
\cline { 3 - 12 } & & MIN & MAX & MEANS & MIN & MAX & MEANS & MIN & MAX & MEANS \\
\hline 1 & 1 & 1 & 1 & 1 & 1 & 1 & 1 & 1 & 1 & 1 \\
\hline 2 & 2 & 1 & 1 & 1 & 1 & 1 & 1 & 1 & 1 & 1 \\
\hline 3 & 3 & 1 & 2 & 1.3 & 1 & 2 & 1.3 & 1 & 2 & 1.6 \\
\hline 4 & 4 & 1 & 2 & 1.5 & 1 & 2 & 1.5 & 1 & 3 & 2 \\
\hline 5 & 5 & 0 & 2 & 1.8 & 1 & 3 & 1.8 & 1 & 5 & 2.6 \\
\hline 6 & 6 & 0 & 2 & 1.3 & 1 & 3 & 2 & 1 & 5 & 2.8 \\
\hline 7 & 7 & 0 & 2 & 1.428 & 1 & 3 & 2.14 & 1 & 5 & 2.85 \\
\hline 8 & 8 & 0 & 2 & 1.5 & 1 & 3 & 2.25 & 1 & 5 & 3.12 \\
\hline 9 & 9 & 0 & 4 & 1.77 & 1 & 4 & 2.44 & 1 & 7 & 3.55 \\
\hline 10 & 10 & 0 & 5 & 2.1 & 1 & 5 & 2.7 & 1 & 10 & 4.2 \\
\hline
\end{tabular}


Tabel 3 merupakan perbandingan antara jumlah obyek terdeteksi dan tidak terdeteksi sebelum dan sesudah proses penggabungan file vektor.

Tabel 3. Hasil Akhir Prosentase Obyek Tidak Terdeteksi

\begin{tabular}{|c|c|c|c|c|}
\hline \multirow{2}{*}{ No } & \multicolumn{2}{|c|}{ Jumlah Obyek Tak Terdeteksi } & \multicolumn{2}{c|}{ Jumlah Obyek Terdeteksi } \\
\cline { 2 - 5 } & $\begin{array}{c}\text { Rata-rata } \\
\text { Vec 1 dan Vec 2 }\end{array}$ & Vec Gabungan & $\begin{array}{c}\text { Rata-rata } \\
\text { Vec 1 dan Vec 2 }\end{array}$ & Vec Gabungan \\
\hline 1 & 1.63145 & 0.6479 & 1.6414 & 2.472 \\
\hline 2 & 1.40525 & 0.6735 & 1.8569 & 2.574 \\
\hline 3 & 1.39185 & 0.8405 & 2.1804 & 2.407 \\
\hline 4 & 1.39185 & 0.8405 & 1.4424 & 2.456 \\
\hline 5 & 1.31535 & 0.7601 & 1.8935 & 2.488 \\
\hline 6 & 1.08825 & 0.6316 & 2.109 & 2.617 \\
\hline 7 & 1.07485 & 0.366 & 2.4325 & 2.882 \\
\hline 8 & 1.3317 & 0.3517 & 1.93 & 2.896 \\
\hline 9 & 1.0896 & 0.5826 & 2.1455 & 2.666 \\
\hline 10 & 1.0762 & 0.4256 & 2.469 & 2.821 \\
\hline 11 & 1.2501 & 0.5352 & 1.9965 & 2.713 \\
\hline Rata-rata & 1.27695 & 0.6050 & 2.0085 & 2.635 \\
\hline
\end{tabular}

Pada Tabel 3 ditunjukkan adanya penurunan kesalahan pendeteksian obyek menggunakan vector gabungan dibandingkan dengan rata-rata vector 1 dan vector 2 sebesar $52.62 \%$ dan adanya peningkatan pendeteksian obyek sebesar $23.78 \%$

\section{Kesimpulan} bahwa:

Berdasarkan hasil dari analisa yang dilakukan pada penelitian ini dapat disimpulkan

1. Proses penggabungan knowledge acquisition dapat dilakukan dengan menggabungkan file vector sebelum proses training.

2. Tingkat akurasi pendeteksian obyek menggunakan vector gabungan mengalami peningkatan dengan menurunnya jumlah obyek yang tidak terdeteksi sebesar $52.62 \%$ dan meningkatnya jumlah obyek yang terdeteksi sebesar $23.78 \%$

\section{Daftar Pustaka}

[1] Jones, M., Viola, P. (2003) Fast multi-view face detection. Mitsubishi Electric Research Lab TR-20003-96, 3:14.

[2] Viola, P., \& Jones, M. J. (2004). Robust Real-Time Face Detection. International Journal of Computer Vision,57(2), 137-154. doi:10.1023/b:visi.0000013087.49260.fb.

[3] Prasetya, D.A, (2012). Deteksi Wajah Metode Viola Jones Pada OpenCV Menggunakan Pemrograman Python. Simposium Nasional RAPI XI FT UMS.ISSN : 1412-9612.

[4] Putro, M.D., Adji, T.B., Winduratna, B.(2012). Sistem Deteksi Wajah dengan Menggunakan Metode Viola-Jones. Seminar Nasional Science, Engineering and Technology.TIF09-3. 
[5] Suharso, Aries,.(2016).Pengenalan Wajah Menggunakan Viola-Jones dan Eigenface Dengan Variasi Posisi Wajah Bebasis Webcam. Vol. 1, No. 2, E-ISSN 2503-054X.

[6] Sajati, H. (2018). The Effect of Peak Signal to Noise Ratio (PSNR) Values on Object Detection Accuracy in Viola Jones Method. Conference SENATIK STT Adisutjipto Yogyakarta,4, 167-174. doi:10.28989/senatik.v4i0.139

[7] Sianturi, Jonatan. (2018). Sistem Pendeteksian Manusia untuk Keamanan Rungan Menggunkan Viola-Jone. Vol. 1, P-ISSN 2549-6247, E-ISSN 2549-6255.

[8] Sun, X., Wu, P., \& Hoi, S. C. (2018). Face detection using deep learning: An improved faster RCNN approach. Neurocomputing,299, 42-50. doi:10.1016/j.neucom.2018.03.030.

[9] Moghimi, M. M., Nayeri, M., Pourahmadi, M., Moghimi, M. K. (2018). Moving vehicle detection using AdaBoost and haar-like feature in surveillance videos, International Journal of Imaging and Robotics, vol. 18, no. 1, pp. 94-106.

[10] Kurniawan, F., Sajati, H., Dinaryanto, O., (2015), Pendeteksian Kepadatan Lalulintas dengan Menggunakan Simpangan Baku Histogram Citra Jalan. Prosiding Seminar Nasional ReTII ke-10 2015.

[11] Li, S. Z., Zhu, L., Zhang, Z., Blake, A., Zhang, H., \& Shum, H. (2002). Statistical Learning of Multi-view Face Detection. Computer Vision - ECCV 2002 Lecture Notes in Computer Science, 67-81. doi:10.1007/3-540-47979-1_5.

[12] Sajati, H., Astuti, Y., (2013), Analisis Dan Perancangan Software Untuk Menentukan Warna Kendaraan Gelap Dan Terang. Jurnal Angkasa Vol. 5 No. 2.

[13] Sajati, H., Astuti, Y., Octaviana, C.H., (2014), Analisis Pemrosesan Paralel Untuk Kompresi Video Pada Jaringan Komputer Berbasis IPv6. Jurnal Ilmiah Angkasa Vol. 6, No. 2.

[14] Sajati, H. (2018), Analisis Kualitas Perbaikan Citra Menggunakan Metode Median Filter Dengan Penyeleksian Nilai Pixel, Jurnal Ilmiah Angkasa Vol. 10, No. 1, PISSN 2085-9503, E-ISSN 2581-1355.

[15] Zein, A. (2018), Pendeteksian Kantuk Secara Real Time Menggunakan Pustaka OPENCV dan DLIB PYTHON, Sainstech Vol. 28, No. 2, pp. 22-26 ISSN 1410 7104 